\title{
A time to operate
}

\author{
Frank A. Baciewicz, Jr, MD
}

\footnotetext{
From the Division of Cardiothoracic Surgery, Wayne State University School of Medicine, Karmanos Cancer Center/Detroit Medical Center, Detroit, Mich.

Disclosures: Author has nothing to disclose with regard to commercial support.

Received for publication Dec 17, 2016; accepted for publication Dec 20, 2016; available ahead of print Jan 31, 2017.

Address for reprints: Frank A. Baciewicz, Jr, MD, Wayne State University School of Medicine, Karmanos Cancer Center/Detroit Medical Center, 3990 John R St, Room 8714, Brush Tower, Detroit, MI 48201 (E-mail: fbaciewi@dmc.org).

J Thorac Cardiovasc Surg 2017;153:841-2

0022-5223/ $\$ 36.00$

Copyright (C 2017 by The American Association for Thoracic Surgery

http://dx.doi.org/10.1016/j.jtcvs.2016.12.026
}

There is a season (turn, turn, turn)

And a time to every purpose, under heaven,

A time to be born, a time to die,

A time to plant, a time to reap

— "Turn! Turn! Turn!
(To Everything
There Is a Season)"
The Byrds, 1965

While The Byrds (circa 1965) and Ecclesiastes 3:1-8 tell us that there is a season for everything, in their article in this issue of the Journal, Murai and colleagues ${ }^{1}$ make the case that the time for valve replacement in patients with left-sided endocarditis who have moderate cerebral complications is early after diagnosis. Murai and colleagues ${ }^{1}$ reviewed their experience from 1990 to 2014 in patients with left-sided infectious endocarditis and cerebral complications. Of the 365 patients treated, 170 were found to have cerebral complications, although this number may underestimate asymptomatic cerebral complications because only $72 \%$ of the patients underwent cerebral imaging with computed tomography or magnetic resonance imaging. Murai and colleagues ${ }^{1}$ subdivided the patients with cerebral complications into moderate and severe subgroups according to the 15-item National Institutes of Health Stroke Scale (NIHSS) scoring system. This NIHSS score ( $\leq 10$ moderate and $\geq 11$ severe) was applied retrospectively in $89 \%$ of the cases. Early surgery was defined as surgery less than 14 days after the diagnosis of endocarditis.

Recent studies by Misfield and associates ${ }^{2}$ and SeltonSuty and colleagues ${ }^{3}$ have reported that $15 \%$ to $33 \%$ of patients with left-sided endocarditis have neurologic findings and that $33 \%$ have no symptoms and have the condition diagnosed only by cerebral imaging. Okita and coworkers, ${ }^{4}$ Sorabella and colleagues, ${ }^{5}$ and Yoshioka and associates $^{6}$ advocate early ( $<7$ days) operation in both patients with asymptomatic and minimally symptomatic disease with either cerebral infarct secondary to emboli or cerebral hemorrhage secondary to leaking aneurysm. neurologic deficits. management.

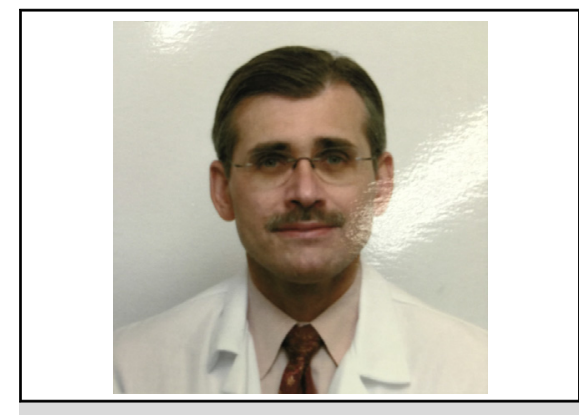

Frank A. Baciewicz, Jr, MD

Central Message

Early valve replacement in patients with leftsided endocarditis and moderate cerebral complications improves outcomes. The NIHSS scale can be used to define moderate versus severe cerebral complications.

See Article page 831.

The potential disadvantages of cardiopulmonary bypass (heparinization and/or hypo/hypertension causing the infarcted or hemorrhagic area to become larger) are countered by improved short- and long-term outcomes. The treatment algorithm has evolved to offer valve replacement to neurologically intact patients with cerebral infarct when indicated and to wait 7 days in the case of neurologically intact patients with cerebral hemorrhage.

Surgeons and multidisciplinary teams have typically not offered early operation to patients with severe findings on neurologic examination or with significant imagining defects. Murai and colleagues ${ }^{1}$ have suggested using the NIHSS scoring system to distinguish moderate from severe

In-hospital mortality of $58 \%$ versus $14 \%$ in severe versus moderate cerebral complication subgroups justified their classification by NIHSS score. Murai and colleagues ${ }^{1}$ reported that approximately half of the patients with moderate cerebral complications underwent early operation and that these patients had superior in-hospital mortality $(3 \%$ vs $24 \%)$ and greater freedom from endocarditis-related complications relative to medical

In addition, early surgical outcome was not affected by whether the patient had cerebral infarction or hemorrhage. Patients with stroke after the diagnosis of infectious endocarditis fared better than those with a stroke diagnosed 
before or simultaneously with endocarditis. Not surprisingly, patients with asymptomatic cerebral complications had better outcomes than those with symptoms.

In the severe cerebral complication category, early operation did not improve outcome. Only 33 patients were in this category, and only 11 underwent early operation.

The study's weaknesses are that the definition of severe versus moderate cerebral complications by the NIHSS score may be arbitrary, and the definition of early surgery as less than 14 days after the diagnosis of infectious endocarditits may be one that 4 surgeons will have 5 different responses to. Murai and colleagues ${ }^{1}$ note that their study was retrospective and encompassed a period during which treatment algorithms have changed. Additionally, not all patients underwent cerebral imagining (only $72 \%$ did so), and some patients $(22 \%)$ were unavailable for follow-up.

Nevertheless, Murai and colleagues ${ }^{1}$ provide evidence that early operation in cases of left-sided endocarditis and moderate cerebral complications improves survival. They make strong points for cerebral imaging in all patients with endocarditis and demonstrate that patients with asymptomatic disease as well as patients who have moderate cerebral complications diagnosed after their left-sided endocarditis will have better survival. They also provide data that most patients with cerebral infarction or hemorrhage can be operated on without fear of worsening their neurologic status.
Most valuable, they offer the NIHSS scoring system to determine the severity of cerebral complications. This may be their most important contribution, because currently decisions on which patients with left-sided endocarditis and cerebral complications should undergo operation is at the discretion of the surgeon or multidisciplinary team. Potentially, the use of this clinical scoring system will assist in the determination of the time to operate.

\section{References}

1. Murai R, Funakoshi S, Kaji S, Kitai T, Kim K, Koyama T, et al. Outcomes of early surgery for infective endocarditis with moderate cerebral complications. J Thorac Cardiovasc Surg. 2017;153:831-40.

2. Misfeld M, Girrback F, Etz CD, Binner C, Aspern KV, Dohmen PM, et al. Surgery for infective endocarditis complicated by cerebral embolism: a consecutive series of 375 patients. J Thorac Cardiovasc Surg. 2014;147:1837-44.

3. Selton-Suty C, Delahaye F, Tattevin P, Federspiel C, Le Moing V, Chirouze C, et al. AEPEI (Association pour l'Etude et la Prévention de l'Endocardite Infectieuse). Symptomatic and asymptomatic neurological complications of infective endocarditis: impact on surgical management and prognosis. PLoS One. 2016; 11:e0158522.

4. Okita Y, Minakata K, Yasuno S, Uozumi R, Sato T, Ueshima K, et al. Optimal timing of surgery for active infective endocarditis with cerebral complications: a Japanese multicentre study. Eur J Cardiothorac Surg. 2016;50:374-82.

5. Sorabella RA, Han SM, Grbic M, Wu YS, Takyama H, Kurlansky P, et al. Early operation for endocarditis complicated by preoperative cerebral emboli is not associated with worsened outcomes. Ann Thorac Surg. 2015;100:501-8.

6. Yoshioka D, Toda K, Sakaguchi T, Okazaki S, Yamauchi T, Miyagawa S, et al; OSCAR study group. Valve surgery in active endocarditis patients complicated by intracranial haemorrhage: the influence of the timing of surgery on neurological outcomes. Eur J Cardiothorac Surg. 2014;45:1082-8. 